\title{
An Evaluation of PAP Smear, Colposcopy, HPV DNA Testing Inscreeningof Cervical Cancer
}

\author{
Dr.S.Sumithra ${ }^{1}$, Dr.R.Manonmani ${ }^{2}$ \\ ${ }^{I}$ Assistant Professor \\ ${ }^{2}$ Associate Professor \\ Department Of Obstetrics and Gynecology/Government Coimbatore Medical College Hospital / \\ The Tamilnadu Dr. MGR Medical University, India.
}

\begin{abstract}
The study was conducted in 200 women who were screened with PAP smear and colposcopy out of them randomly selected 70 women underwent HPV DNA testing. In the study group maximum incidence of squamous intraepithelial lesion/invasive cancer was seen in the age group of over 40 years(70.7\%).Of the women who underwent colposcopy there were 64(32\%) women with abnormal findings, of which 39(60.9\%) were found to have premalignant or malignant lesion.Among the women in whom Pap smear was taken $30(15 \%)$ women had abnormal cytology and 20 of the 30 (66.7\%) women had SIL/CA in their biopsy.In the 70 women for whom HPV DNA testing was done, 41 (58.6\%) were HPV positive and 29 (41.4\%) were negative.HPV 16 was most common among the women tested positive for HPV.The sensitivity of Pap smear was 48.8\% and specificity was $93.7 \%$ PPV and NPV was 66.7\% and 87.6\%.The colposcopy showed a sensitivity of 92.7\% and specificity of $83.6 \%$ the PPV and NPV were 59.4\% and $97.8 \%$ respectively.Colposcopy had a higher sensitivity and PAP smear had a higher specificity.On combining Cytology and HPV DNAtestthe sensitivity was $100 \%$ and the specificity was $60.2 \%$. The cotesting of cytology with HPV DNA had 100\% negative predictive value.
\end{abstract}

Keywords: Cervical cancer, Colposcopy,HPV DNA test,Pap smear

\section{Introduction}

Cancer of uterine cervix is the secondmost common cancer affecting women worldwide. One out of every five women in the world suffering from this disease belongs to India.According to the Indian Council of Medical Research (ICMR), the incidence of cervical cancer in India varies from 20 to 35 / 100,000 women between the age group of 35 years to 64 years[1].

Although cytology screening has resulted in a large reduction in the cervical cancer burden in our country, incidence rates continue to be unabated for want of effective screening programs. More than threefourths of these patients are diagnosed at advanced stages leading to poor prospects of long-term survival and cure. It is well established that invasive cervical carcinomas develop from pre-existing, slowly progressing intraepithelial dysplastic precursor lesions. The direct precursor to invasive squamous carcinoma is a high-grade squamous intraepithelial lesion (HSIL). The object of screening a woman for cervical cancer is to reduce the incidence and mortality by detecting and treating the pre-cancerous lesions.

One of the prerequisites for effective screening is the availability of a suitable cervical screening test that has adequate sensitivity and specificity for detection of precancerous lesions and that yields reproducible results. Such a test should be cheap, simple, and easy to apply, without side effects or complications, as painless as possible, and socioculturally acceptable.

Following its introduction by Papanicoloau in 1927, exfoliativecervicovaginal cytology has been extensively investigated and used as a screening test for cervical cancer. Regular population based screening using Pap smear cytology is now internationally accepted as a screening method for cervical cancer

A better understanding of the natural history of cervical cancer and also the increasing evidence for the putative role of the Human Papilloma Virus (HPV) on the epithelium of lower genital tract, and genesis of cervical cancer has now prompted investigators to find alternatives to conventional exfoliative cytology. Colposcopy and HPV DNA testing had become an essential tool in diagnosis of premalignant and malignant lesions of cervix.

Introducing cervical screening programs to areas without them previously results in a $60 \%$ to $90 \%$ reduction in cervical cancer rates within 3 years[2]. Control of cervical cancer in India would have a major global impact as it accounts for a fifth of the world burden of cervical cancer. The magnitude of the problem due to cervical cancer, and the potential for its prevention, makes it imperative to identify a feasible strategy for screening in the Indian settings. 


\section{AIM}

A. To evaluate the sensitivity and specificity of PAP smear and Colposcopy in screening of premalignant and malignant lesion of cervix.

B. To evaluate the usefulness of HPV DNA testing in screening for cervical cancer.

\section{Materials And Methods}

This is a prospective study conducted in the Department of Obstetrics and Gynecology, Government Coimbatore Medical College from May 2015 to June 2016. The study included 200 randomly selected women who attended our gynecology OPD and fulfilled the inclusion criteria.

\subsection{Inclusion Criteria:}

a) Women of age 20-70 years attending gynecologyOPD with complaints of persistent vaginal discharge, postcoitalbleeding,intermenstrual or perimenopausal bleeding.

b) Women with abnormal cervical lesions like cervical hypertrophy, erosion, ulceration, bleeding on touch.

\subsection{Exclusion Criteria -}

Menstruation,Pregnancy,Postpartum,Already treated for cancer cervix,Age $<20$ and $>70$ years

\subsection{PAP Smear}

Patient was counseled and informed consent was obtained. After relevant social, obstetric, gynecologicaland medical history was obtained, clinical examination was done.

With patient in lithotomy and under illumination, Cusco's self-retaining speculum was introduced into the vagina, cervix visualized and Pap smear was taken with anAyre's spatula rotating $360^{\circ}$ around thesquamocolumnar junction, cervical cells were collected and fixed on a slide with isopropyl alcohol.

\subsection{Colposcopy}

With the use of the colposcopy cervix was examined under green filter for abnormal vasculature. $3 \%$ acetic acid applied completely and cervix evaluated by meticulous examination of each quadrant of the entire transformation zone. The findings were recorded, followed by application of Lugols iodine findings noted. Colposcopy directed biopsy were taken from abnormal areas with a punch biopsy forceps and sent for HPE.

\subsection{Detection of HPV infection and genotyping}

Seventy randomly selected women from the study underwent HPV DNA testing by PCR. Cervical scarping were collected using a sterile disposable cervical brush in a sample collection buffer(phosphate buffer saline (PBS): $\mathrm{pH}$ 7.4) for detection of HPV DNA by PCR. Detection of HPV infection and genotyping was performed by Polymerase Chain Reaction.HPV kit was purchased from Genei,India.This type -specific polymerase chain reaction (TS - PCR)uses two consensus sequence primer pairs within the E6 and E7ORFs to amplify HPV DNA. The PCR products size varying from 230-270bp are subjected to agarose gel electrophoresis and the HPV genotypes are identified based on the base pairs.

\section{Results}

This study included a total of randomly selected 200 symptomatic women. The demographic characteristics of the women, according to their age, age at marriage, duration of married life, age at first child birth, parity are described.

The mean age of the study group was 40.6 years. The distributions of premalignant and malignant disease were highest in the women over the age of 40 yrs. Of the 107 women married between the age of 15-19 years $82(76.6 \%)$ were normal $25(23.4 \%)$ had Squamous Intraepithelial Lesion or invasive carcinoma. The analysis showed that the women who had the first sexual contact at the age less than 19 years had higher proportion of malignant and premalignant lesion of cervix (23.4\%). The women with the age of marriage over 30 years were only 2 and both were normal.

The analysis proved the higher the parity more the proportion of SIL or invasive cancer. The highest proportions of $44.4 \%$ were found among the women with parity $>5$. There was no SIL in the 4 women who were either nulliparous or with one child.

Among the 200 women the commonest complaint was discharge per vaginumof which $23.5 \%$ had SIL or invasive CA. Of the women who presented with postcoital bleeding $62.5 \%$ had SIL or invasive carcinoma followed by women with post menopausal bleeding $(28.6 \%)$.

Of the 200 women screened with PAP smear85\% had inflammatory smear, $7 \%$ had normal cytology and $15 \%$ had abnormal cytology. On correlation with HPE of the women who had inflammatory smear on 
cytology $11.5 \%$ had SIL/CA.Of the women with ASCUS,LSIL,HSILin PAP smear 42.9\%,66.7\%,83.3\% were found to have SIL /CA respectively.

On colposcopic examination $39.5 \%$ of the study group had normal colposcopic appearance, erosion was seen in $22.5 \%$,punctation and Mosaic pattern was seen in 5.5 and 3.5\% respectively.Nine (4.5\%) of the 200 women had unsatisfactory colposcopy.On application of acetic acid 64 of the women had abnormal colposcopic finding. Premalignant or malignant lesion were found in $47.8 \%$ of women with acetowhite area only, $81.6 \%$ women with AW area with punctuation and $100 \%$ of women with AW area with mosaic pattern. On application of Lugol'siodine 44 had negativity of which $65.9 \%$ had SIL/Invasive cancer.

Of the 200 colposcopy directed biopsy, $79.5 \%$ showed features of cervicitis.LSIL and HSIL were found in $13.5 \%$ and $5.5 \%$ of women respectively. Three women showed evidence of invasive cancer.

On correlation with HPE, 79 women with normalcolposcopicappearance, $2.5 \%$ had SIL/CA.Among the 45 women with erosion, $2.2 \%$ hadSIL/CA. Of the 64 women with abnormal colposcopic finding $39(60.9 \%)$ had SIL/CA.

Of the 70 randomly selected women, who underwent HPV DNA testing, 41 tested positive for HPV and 29 tested negative. Among the 11 women with HSIL 10 tested positive for either HPV 16 or 18 .Of the 23 women with LSIL, 15 were positive for HPV 16, 4 for HPV 18, 2 for others (HPV 31 \& 45). All three women with pre-clinical malignancy were positive for either HPV 16 or 18.

On comparing PAP smear and HPV DNA and correlating with histopathology, 20 women who had both cytology and HPV DNA negative had normal or cervicitis in histopathology. Of the 9 women with abnormal cytology and HPV DNAnegative, 6 had normal/inflammatory finding in HPE and 3 had SIL. In women with both test positive 3 had normal HPE and 17 had SIL. Among the women with normal cytology and HPV positive, 17 were found to have SIL and 4 had inflammatory histology.

On combining PAP smear and HPV DNA test and correlating with HPE the sensitivity was $100 \%$, specificity was $60.2 \%$. PPV and NPV were $74 \%$ and $100 \%$ respectively.

\section{Discussion}

The highest incidence of carcinoma cervix is reported to be seen among the woman in the age group of 35 to 45 years[3]. In our analysis the age wise distribution of SIL or invasive cancer showed a higher incidence among the women in their $4^{\text {th }}$ or $5^{\text {th }}$ decade. A similar study done by Pontus Naucler et al showed the cervical cancer peaks at around the age of 40years[4].

Increased incidence of CIN was found among the women who married at a younger age and hence started early coital activity. Of the women married at the age less than 19 years in the study group 25 (23.4\%) had SIL where as in women who married over the age of $25 \mathrm{yrs}$ it was $15.4 \%$.

This in all probability appears to be related to the prolonged sexual activity as marriage at an early age is very common in India. It was found in UK by a National study on cervical cancer done by Green et al that the risk of squamous cell carcinoma was strongly related independently to the age at the first intercourse [5]. In our study multiparous women $(\geq 3)$ contribute to the major proportion of cases with SIL. Xavier Bosch et al reported increased risk of SIL with high parity[6]. In a study done by Hildesheim. A et al42\% of HSIL/CA was attributed to multiparity[7] . Green et al noticed that risk of cervical cancer was associated with high parity and the risk increased with early age at the first child birth.

Regarding the complaints most of the women presented with vaginal discharge, of which 25 (23.2\%) had SIL. The incidence SIL (62.5\%) was highest in women who presented with post coital bleeding which was similar to studies conducted by Shalini et al[8]. The commonest per speculum finding was ectopy of cervix seen in 97 women, of which $27.5 \%$ had SIL.

The only screening test which has been universally accepted and has stood the test of time is the Papanicolaou smear test for the early detection of cervical cancer.Modeling of data from South Africa suggests that even screening women just once in their lives, at age 35 could reduce cervical cancer mortality by 26 percent[9].

In our study PAP smear was taken in all women, of whom $30(15 \%)$ had abnormal cytology. False negative rates were $10.5 \%$ in whom the disease was undiagnosed. False positive rates were $5 \%$ in whom the disease was over diagnosed.The sensitivity of Pap smear in our study was $48.8 \%$, specificity was $93.7 \%$, PPV was $66.7 \%$ and NPV was $87.6 \%$. The comparison between our study and other similar studies showed the senisitivity and specificity to be $57.4 \%$ and $98.6 \%$ by Surendra S Shastri et al, $76 \%$ and $97.09 \%$ by Ekta Singh et al, $69.2 \%$ and $63.7 \%$ by katyalsurabi et al, $50 \%$ and $78 \%$ by AnuradhaKhanna et al, $20 \%$ and $91.25 \%$ by sukpreeth et al.[10,11,12,13,14]

All women in the study sample underwent colposcopic evaluation , out of the 200 women screened 136 (68\%) had normal colposcopic findings, in the remaining 64 women who had abnormal colposcopic finding 24 (37.5 \%) had LSIL, 11 (17.1\%) had HSIL, 3 (4.6\%) had invasive carcinoma the remaining 26 (40.6\%) were false negatives. 
On application of acetic acid 46 women showed aceto white areas without abnormal vascular features, of which $22(47.8 \%)$ had SIL. 7 women who had aceto white area with mosaic pattern had SIL. 11 women showed punctuations out of which $9(81.6 \%)$ had SIL.On Application of Lugol's Iodine 44 women were negative and $29(65.9 \%)$ had SIL, 71 women were partially positive of which $11(15.4 \%)$ had SIL.

The sensitivity of colposcopy in our study was $92.7 \%$, specificity was $83.6 \%$, PPV was $59.4 \%$ and NPV was $97.8 \%$. Various other studies showed sensitivity and specificity of colposcopy as $100 \%$ and $96.4 \%$ by katyalSurabi et al,93\% and $92.6 \%$ by Anuradhakhanna et al, $95 \%$ and $63.5 \%$ bySukhpreeth Singh et al $[12,13,14]$

Colposcopy proved helpful in distinguishing the normal cervix from those with high grade lesion and the results are instant. The colposcopy is an excellent means for follow up of patients with abnormal cytology. It reduces the false negative rates. The colposcopy is used not only in the evaluation of cervix, but the lower female genital tract as the whole. The limitation of colposcopy includes the transformation zone may not be visible fully, needs expertise and time consuming.

70 randomly selected women underwent HPV testing. Out of those 41 were tested to be positive (58.6 \%), 29 were tested negative. In our study most common was HPV 16 which is in concordance with study by SilviaFranceschietal[15] and the prevalence of HPV 16 in the study group was $38.5 \%$ and HPV 18 was 17.1 $\%$.The sensitivity of HPV testing in our study was $91.8 \%$, Specificity was $78.8 \%$, PPV was $82.5 \%$ and NPV was $89.9 \%$ in detecting all grades of SIL. The study by Katyalsurabi et al showed sensitivity and specificity of $92.3 \%$ and $84 \%$, which is similar to that this study[12]. Whereas studies by Surendra et al and Samuel et al show sensitivity $62 \%$ and $73 \%$ and specificity of $93.5 \%$ and $62 \%$ respectively $[10,16]$.

In our study the sensitivity of HPV testing for detecting HSIL and above lesions had a sensitivity of 92.9\% and Specificity of $50.8 \%$.In studies conducted by RengaswamySankarnarayanan et al HPV had a sensitivity of $45.7-80.9 \%$ and Specificity of $91.7-94.6 \%$, Ekta Singh et al had a sensitivity of $90.91 \%$ and Specificity of $51.35 \%$, Samuel Rathinam et al had a sensitivity of $90 \%$ and Specificity of 51\%[16]. The wide variation in sensitivity and Specificity may be due to variation in the quality of sample collection and reference standards[18,11,16].

In our study on combining cytology with HPV testing the sensitivity was raised to $100 \%$ and Specificity $60.2 \%$ similar results were shown by Ekta Singh et al sensitivity of $100 \%$ and Specificity of 68.1 $\%$, KatyalSurabi et al had sensitivity of $100 \%$ and Specificity of $61.9 \%$.[11,12]

HPV DNA test can improve the detection rate of HSIL and also reduce the referral rate by safely allowing the HPV negative woman with equivocal cytology or LSIL to be followed up with cytology at normal intervals.

Any women aged 30 years who had a negative test results on both cytology and HPV DNA should be re screened no more frequently than 3 years. The combined use of these modalities has been shown to increase the sensitivity, but also decrease specificity and increase cost. However it has been estimated that the increase in screening interval will offset the cost of this new screening regime [19].

VI. Tables And Figures.

Table.1. Distribution According To Age

\begin{tabular}{|c|c|c|c|c|c|c|c|c|c|c|c|}
\hline \multirow[b]{2}{*}{ AGE } & \multirow{2}{*}{$\begin{array}{l}\bar{\Xi} \\
\text { है } \\
\bar{Z}\end{array}$} & \multicolumn{2}{|c|}{ NORMAL } & \multicolumn{2}{|c|}{ LSIL } & \multicolumn{2}{|c|}{ HSIL } & \multicolumn{2}{|l|}{$\mathrm{CA}$} & \multicolumn{2}{|c|}{ TOTAL } \\
\hline & & No. & $\%$ & No. & $\%$ & No. & $\%$ & $\begin{array}{l}\text { No } \\
\text {. }\end{array}$ & $\%$ & No. & $\%$ \\
\hline $21-30$ & 25 & 23 & 92 & 2 & 8 & - & - & - & - & 2 & 8 \\
\hline $31-40$ & 78 & 68 & 87.2 & 8 & 10.3 & 2 & 2.6 & - & - & 10 & 12.8 \\
\hline $41-50$ & 67 & 50 & 74.6 & 11 & 16.4 & 5 & 7.5 & 1 & 1.5 & 17 & 25.3 \\
\hline $51-60$ & 24 & 13 & 54.2 & 6 & 25 & 4 & 16.7 & 1 & 4.2 & 11 & 45.8 \\
\hline \multirow[t]{2}{*}{$>60$} & 6 & 5 & 83.3 & - & - & - & - & 1 & 16.7 & 1 & 16.7 \\
\hline & 200 & 159 & & 27 & & 11 & & 3 & & 41 & \\
\hline
\end{tabular}

Table 2.Distribution According To Age of Marriage

\begin{tabular}{|c|c|c|c|c|c|c|c|c|c|c|c|}
\hline \multirow{3}{*}{ 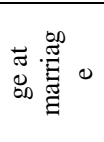 } & \multirow{3}{*}{$\begin{array}{l}\bar{\Xi} \\
\stackrel{\Xi}{\Xi} \\
\text { 乙 }\end{array}$} & \multirow{2}{*}{\multicolumn{2}{|c|}{ Normal }} & \multicolumn{8}{|c|}{ SIL } \\
\hline & & & & \multicolumn{2}{|c|}{ LSIL } & \multicolumn{2}{|c|}{ HSIL } & \multicolumn{2}{|c|}{$\begin{array}{c}\text { Invasive } \\
\text { CA }\end{array}$} & \multicolumn{2}{|c|}{ Total } \\
\hline & & $\mathrm{No}$ & $\%$ & No & $\%$ & No & $\%$ & No & $\%$ & No & $\%$ \\
\hline $15-19$ & 107 & 82 & 76.6 & 15 & 14 & 8 & 7.5 & 2 & 1.9 & 25 & 23.4 \\
\hline $20-24$ & 78 & 64 & 82.1 & 10 & 12.8 & 3 & 3.8 & 1 & 1.3 & 14 & 17.9 \\
\hline $25-29$ & 13 & 11 & 84.6 & 2 & 15.4 & - & - & - & - & 2 & 15.4 \\
\hline $30-34$ & 2 & 2 & 100 & - & - & - & - & - & - & - & - \\
\hline
\end{tabular}


Table: 3. Distribution According to parity

\begin{tabular}{|c|c|c|c|c|c|c|c|c|c|c|c|}
\hline \multirow{2}{*}{ Parity } & \multirow{2}{*}{ Number } & \multicolumn{2}{|c|}{ Normal } & \multicolumn{9}{|c|}{ SIL } \\
\cline { 3 - 12 } & & No & $\%$ & \multicolumn{2}{|c|}{ LSIL } & \multicolumn{2}{c|}{ HSIL } & \multicolumn{2}{|c|}{ Invasive CA } & \multicolumn{2}{c|}{ Total } \\
\hline 0 & 1 & 1 & - & - & - & - & - & - & - & - & - \\
\hline 1 & 3 & 3 & - & - & - & - & - & - & - & - & - \\
\hline 2 & 58 & 53 & 91.4 & 4 & 6.9 & 1 & 1.7 & - & - & 5 & 8.6 \\
\hline 3 & 73 & 63 & 86.3 & 8 & 11 & 2 & 2.7 & - & - & 10 & 13.7 \\
\hline 4 & 56 & 34 & 60.7 & 14 & 25 & 6 & 10.7 & 2 & 3.6 & 22 & 39.3 \\
\hline$>5$ & 9 & 5 & 55.6 & 1 & 11.1 & 2 & 22.2 & 1 & 11.1 & 4 & 44.4 \\
\hline & $\mathbf{2 0 0}$ & 159 & & 27 & & 11 & & 3 & & 41 & \\
\hline
\end{tabular}

Table 4. Distribution of CIN according the complaints

\begin{tabular}{|c|c|c|c|c|c|c|c|c|c|c|c|}
\hline \multirow{3}{*}{ Complaints } & \multirow{3}{*}{ Number } & \multirow{2}{*}{\multicolumn{2}{|c|}{ Normal }} & \multicolumn{8}{|c|}{ SIL } \\
\hline & & & & \multicolumn{2}{|c|}{ LSIL } & \multicolumn{2}{|c|}{ HSIL } & \multicolumn{2}{|c|}{ Invasive CA } & \multicolumn{2}{|c|}{ Total } \\
\hline & & No & $\%$ & No & $\%$ & No & $\%$ & No & $\%$ & No & $\%$ \\
\hline $\begin{array}{l}\text { White } \\
\text { discharge }\end{array}$ & 123 & 94 & 76.4 & 22 & 17.8 & 5 & 4 & 2 & 1.6 & 29 & 23.5 \\
\hline $\begin{array}{l}\text { Abdominal } \\
\text { Pain }\end{array}$ & 36 & 33 & 91.7 & 3 & 8.3 & - & - & - & - & 3 & 8.3 \\
\hline $\begin{array}{l}\text { Inter } \\
\text { Menstrual } \\
\text { Bleeding }\end{array}$ & 8 & 7 & 87.5 & - & - & 1 & 12.5 & - & - & 1 & 12.5 \\
\hline $\begin{array}{l}\text { Post coital } \\
\text { bleeding }\end{array}$ & 8 & 3 & 37.5 & 1 & 12.5 & 3 & 37.5 & 1 & 12.5 & 5 & 62.5 \\
\hline $\begin{array}{l}\text { Post } \\
\text { menopausal } \\
\text { bleeding }\end{array}$ & 7 & 5 & 71.4 & - & - & 2 & 28.6 & - & - & 2 & 28.6 \\
\hline Others & 18 & 17 & 94.4 & 1 & 5.6 & - & - & - & - & 1 & 5.6 \\
\hline
\end{tabular}

Table.5. Results of PAP smear

\begin{tabular}{|l|l|l|}
\hline PAP smear & Number & $\%$ \\
\hline Normal & 14 & 7 \\
\hline Normal, cervicitis & 156 & 78 \\
\hline LSIL & 15 & 7.5 \\
\hline HSIL & 6 & 3 \\
\hline ASCUS & 7 & 3.5 \\
\hline Invasive Cancer & 2 & 1 \\
\hline Total & 200 & 200 \\
\hline
\end{tabular}

Table .6.Colposcopic Findings

\begin{tabular}{|l|l|l|}
\hline Colposcopy & NUMBER & $\%$ \\
\hline normal & 79 & 39.5 \\
\hline Erosion & 45 & 22.5 \\
\hline AW areas & 46 & 23 \\
\hline Punctation & 11 & 5.5 \\
\hline Mosaic & 7 & 3.5 \\
\hline Polyp & 3 & 1.5 \\
\hline Unsatisfactory & 9 & 4.5 \\
\hline Total & 200 & 100 \\
\hline
\end{tabular}

Table 7.Acetic acid application:

\begin{tabular}{|l|l|l|l|}
\hline Change in TZ & No & CIN & \% \\
\hline AW areas & 46 & 22 & 47.8 \\
\hline Mosaic & 7 & 7 & 100 \\
\hline Punctuation & 11 & 9 & 81.6 \\
\hline
\end{tabular}


Table 8. Iodine application

\begin{tabular}{|l|l|l|l|}
\hline Iodine change & No & CIN & \% \\
\hline Positive & 85 & 1 & 1.2 \\
\hline Partial positive & 71 & 11 & 15.4 \\
\hline Negative & 44 & 29 & 65.9 \\
\hline
\end{tabular}

Table 9.Histopathology

\begin{tabular}{|l|l|l|}
\hline HPE & Number & No \\
\hline Normal, cervicitis,polyp & 159 & 79.5 \\
\hline LSIL & 27 & 13.5 \\
\hline HSIL & 11 & 5.5 \\
\hline Invasive Cancer & 3 & 1.5 \\
\hline Total & 200 & 100 \\
\hline
\end{tabular}

Table 10.Correlation of Colposcopy with Histopathology

\begin{tabular}{|c|c|c|c|c|c|c|c|c|c|c|c|}
\hline \multirow{3}{*}{ Colposcopy } & \multirow{3}{*}{ NUMBER } & \multirow{2}{*}{\multicolumn{2}{|c|}{ NORMAL }} & \multirow{2}{*}{\multicolumn{2}{|c|}{ LSIL }} & \multirow{2}{*}{\multicolumn{2}{|c|}{ HSIL }} & \multirow{2}{*}{\multicolumn{2}{|c|}{ CA }} & & \\
\hline & & & & & & & & & & \multicolumn{2}{|c|}{ TOTAL } \\
\hline & & No. & $\%$ & No. & $\%$ & No. & $\%$ & No. & $\%$ & No. & $\%$ \\
\hline Normal & 79 & 77 & 97.4 & 2 & 2.5 & 0 & 0 & 0 & 0 & 2 & 2.5 \\
\hline Erosion & 45 & 44 & 97.7 & 1 & & 0 & 0 & 0 & 0 & 1 & 2.2 \\
\hline $\mathrm{AW}$ areas & 46 & 24 & 52.2 & 16 & 34.7 & 4 & 8.7 & 2 & 4.3 & 22 & 47.8 \\
\hline Punctation & 11 & 2 & 18.2 & 5 & 45.5 & 4 & 36.4 & 0 & 0 & 9 & 81.8 \\
\hline Mosaic & 7 & - & - & 3 & 42.9 & 3 & 42.9 & 1 & 14.3 & 7 & 100 \\
\hline Polyp & 3 & 3 & - & - & - & - & - & - & - & - & \\
\hline Unsatisfactory & 9 & 9 & - & - & - & - & - & - & - & - & - \\
\hline
\end{tabular}

Table 9.Correlation of cytology with Histopathology

\begin{tabular}{|c|c|c|c|c|c|c|c|c|c|c|c|c|}
\hline \multirow{3}{*}{ PAP } & \multirow{3}{*}{ Number } & \multirow{3}{*}{$\%$} & \multirow{2}{*}{\multicolumn{2}{|c|}{ Normal }} & \multicolumn{8}{|c|}{ abnormal } \\
\hline & & & & & \multicolumn{2}{|c|}{ LSIL } & \multicolumn{2}{|c|}{ HSIL } & \multicolumn{2}{|l|}{$\mathrm{CA}$} & \multicolumn{2}{|c|}{ TOTAL } \\
\hline & & & No. & $\%$ & No. & $\%$ & No. & $\%$ & No. & $\%$ & No. & $\%$ \\
\hline $\begin{array}{l}\text { Normal } \\
\text { Smear }\end{array}$ & 14 & 7 & 11 & 78.6 & 3 & 21.4 & - & - & - & - & 3 & 21.4 \\
\hline $\begin{array}{l}\text { Inflammatory } \\
\text { Smear }\end{array}$ & 156 & 78 & 138 & 88.5 & 14 & 9 & 4 & 2.6 & - & - & 18 & 11.5 \\
\hline ASCUS & 7 & 3.5 & 4 & 57.1 & 1 & 14.3 & 2 & 28.6 & - & - & 3 & 42.9 \\
\hline LSIL & 15 & 7.5 & 5 & 33.3 & 9 & 60 & 1 & 6.7 & - & - & 10 & 66.7 \\
\hline HSIL & 6 & 3 & 1 & 16.7 & - & - & 4 & 66.7 & 1 & 16.7 & 5 & 83.3 \\
\hline CA & 2 & 1.0 & - & - & - & - & - & - & 2 & 100 & 2 & 100 \\
\hline & 200 & 100 & 159 & & 27 & & 11 & & 3 & & & \\
\hline
\end{tabular}

Table 10.Colposcopy

\begin{tabular}{|l|l|l|l|l|l|l|l|l|}
\hline \multicolumn{2}{|l|}{ Results } & \multicolumn{2}{l|}{ HPE } & Sensitivity & Specificity & PPV & NPV \\
\cline { 3 - 5 } \multicolumn{2}{|l|}{} & pos & Neg & total & & & & \\
\hline \multirow{2}{*}{ colposcopy } & Pos & 38 & 26 & 64 & $92.7 \%$ & $83.6 \%$ & $59.4 \%$ & $\begin{array}{l}97.8 \\
\%\end{array}$ \\
\cline { 2 - 5 } & Neg & 3 & 133 & 136 & & & & \\
\cline { 2 - 5 } & total & 41 & 159 & 200 & & & & \\
\hline
\end{tabular}

Table 11.PAP Smear

\begin{tabular}{|l|l|l|l|l|l|l|l|l|}
\hline \multicolumn{2}{|l|}{ Results } & \multicolumn{2}{|l|}{ HPE } & Sensitivity & Specificity & PPV & NPV \\
\cline { 2 - 5 } \multicolumn{2}{l|}{} & pos & Neg & total & & & \\
\hline \multirow{3}{*}{ PAP } & Pos & 20 & 10 & 30 & $48.8 \%$ & $93.7 \%$ & $66.7 \%$ & $87.6 \%$ \\
\cline { 2 - 5 } & Neg & 21 & 149 & 170 & & & \\
\cline { 2 - 5 } & total & 41 & 159 & 200 & & & \\
\hline
\end{tabular}

Table 12.HPV DNA testing

\begin{tabular}{|l|l|l|l|l|}
\hline HPV & Neg & HPV 16 & HPV 18 & others \\
\hline Normal/cervicitis & 26 & 6 & 1 & 0 \\
\hline LSIL & 2 & 15 & 4 & 2 \\
\hline HSIL & 1 & 4 & 6 & 0 \\
\hline Inv CA & - & 1 & 2 & 0 \\
\hline
\end{tabular}


Table 13.Correlation between PAP and HPV DNA test with HPE

\begin{tabular}{|l|l|l|}
\hline & Normal/inflammatory & SIL/CA \\
\hline $\begin{array}{l}\text { Cytology positive } \\
\text { HPV DNA positive }\end{array}$ & 3 & 17 \\
\hline $\begin{array}{l}\text { Cytology positive } \\
\text { HPV Negative }\end{array}$ & 6 & 3 \\
\hline $\begin{array}{l}\text { Cytology negative } \\
\text { HPV Positive }\end{array}$ & 4 & 17 \\
\hline $\begin{array}{l}\text { Cytology negative } \\
\text { HPV Negative }\end{array}$ & 20 & 0 \\
\hline
\end{tabular}

Table 14.Comparison of PAP smear, Colposcopy, HPV DNA test, PAP and HPV DNA test

\begin{tabular}{|l|l|l|l|l|}
\hline TEST & PAP smear & Colposcopy & $\begin{array}{l}\text { HPV } \\
\text { DNA } \\
\text { testing }\end{array}$ & $\begin{array}{l}\text { PAP and HPV } \\
\text { test }\end{array}$ \\
\hline Sensitivity & $48.8 \%$ & $92.7 \%$ & $91.8 \%$ & $100 \%$ \\
\hline Specificity & $93.7 \%$ & $83.6 \%$ & $78.8 \%$ & $60.2 \%$ \\
\hline Positive predictive value & $66.7 \%$ & $59.4 \%$ & $82.5 \%$ & $74 \%$ \\
\hline Negative predictive value & $87.6 \%$ & $97.8 \%$ & $89.9 \%$ & $100 \%$ \\
\hline
\end{tabular}

\section{Conclusion}

Screening for cervical cancer remains an important health and economic concern in the throughout the world. All cervical cancer screening programs share challenges in their efforts to educate women about disease prevention and to persuade women to accept screening.

The Pap smear though has been the basis for screening for cervical cancer, has a low sensitivity and a high false negative rates. Colposcopy has a higher sensitivity than PAP smear .It excellent tool in evaluating cervical lesions. The results of colposcopy are immediate and its importance lies in the diagnosis and management of cervical lesions with use of colposcopy.

HPV DNA testing has a higher sensitivity and negative predictive value than PAP smear and it's not influenced by the inflammatory lesion of the vagina. When combinedPAP smear with HPV DNA test, sensitivity and negative predictive value are high. The currently available HPV DNA tests are too expensive and technologically demanding for widespread use, even though their potential for identifying high-grade dysplasia. Hence wherever feasible and affordable HPV DNA test and PAP smear can be combined for better sensitivity. HPV DNA test, due to its high negative predictive value, is used in triage of women with borderline cytology.

Incorporating HPV DNA testing into cervical cancer prevention activities may have to wait for the development of HPV tests that are less expensive than existing options, and easier to use in non-laboratory settings. For the present day, Colposcopy proves to be indispensible method in detecting, evaluating and managing cervical lesion, as long as their limitations are borne in mind.

\section{Reference}

[1]. Purandare C.N, Down staging of cervical cancer in resource poor settings, J ObstetGynecol India Vol 60 No 2 May/June 2010 pp 205-206

[2]. A.Nandakumar,T.Ramnath\&Meeshachaturvedi ,The magnitude of cancer in India ,Indian J Med Res 130,Sep 2009,pp219-221

[3]. VG Padubidri ,SN.Daftary, Shaw textbook of gynecology, $16^{\text {th }}$ edition, Chapter 38,cervical intra epithelial neoplasia,carcinoma cervix pp 485(Elsevier, NewDelhi)

[4]. Pontus Naucler et al., Human Papilloma Virus and Papanicolaou tests to screenfor cervical cancer, The New England Journal of Medicine, 357:16 Oct 182007.

[5]. Green .J et al, Risk factors for adenocarcinoma and squamous cell carcinoma of cervix in women aged 20-44years : the U.K National case control study of cervical cancer, British Journal of cancer 2003,89,2078-2086.

[6]. Xavier F Bosch,you-Lin Qiao, Xavier Castellsague, The Epidemiology o Human Papilloma infection and its association with cervical cancer,Int journal of Gynecology and obstetrics (2006)94(supplements 1),S8-S21.

[7]. Hildesheim A,Herrero R, HPV co-factors related to the development of cervical cancer, results from a population based study in Costa Rica,British Journal Of Cancer (2001)84(9),1219-1226.

[8]. Shalini et al,How alarming is Post Coital Bleeding - A cytologicColposcopic and Histopathologic evaluation ,GynecolObstet Invest 1998,45,250-208.

[9]. Goldie MD et al Policy Analysis of cervical cancer screening strategies in Low - Resource setting clinical benefits and cost effectiveness.JAMA,June 27,2001-vol 285, No24.,3107

[10]. Surendra S. Shastri, KetayunDinshaw, Geetanjali Amin, Concurrent evaluation of visual, cytological and HPV testing as screening methods for the early detection of cervical neoplasia in Mumbai, India, Bulletin of the World Health OrganizationMarch 2005, 83 (3).

[11]. Ektasingh et al,Evaluation of detection methods of cervical neoplasia-preventable deaths not prevented yet. Asian Journal of Obs and gynecpractice, Vol.1 Jan -Mar 2010

[12]. Katyalsurabhi,MehotraRagini,Complementary procedures in cervical cancer screening in low resource settings.JObstetgynecol of India (July-Aug 2011)61(4):436-438 
[13]. AnuradhaKhanna,RichaGupta,Comprehensive Evaluation of cervical Cancer. Indian J. prev. Soc.MedVol 3\&4.2003

[14]. Sukhpreet L Singh, Nayana A, Dastur, Murari. S, Nanavati, A comparison of colposcopy and papanicolaussmear :sensitivity,specificity and predictive value, BHJ, No 4, vol 42, Oct 2000.

[15]. Silvia Francheschi, ThangarajanRajkumar, Salvatore Vaccarella, VendhanGajalakshmi., Human Paillomavirus and risk factors for cervical cancer in Chennai,India:A case control study, Int J.cancer:107,127-133(2003)

[16]. Samuel Ratnam, Eduardo L. Franco and Alex Ferenczy Human Papillomavirus Testing for Primary Screening of cervical cancer precursors. Cancer Epidemiol Biomarkers Prev 2000;9:945-951.

[17]. RengaswamySankaranarayanan,M.D.,etalHPVScreeningfor cervical cancer in rural Indian engl j med 360:14 nejm.orgApril 2 ,2009

[18]. Rengaswamysankaranarayanan ,Ramdaschatterji,surendra S shastri,Accuracy of Human papilloma virus testing in primary screening of cervical neoplasia :results from multicentric studies in India.Int.J.Cancer:112,341-347(2004)

[19]. ACOG Practice Bulletin no.109:cervical cytologyscreening ACOG Committee on Practice Bulletins- Gynecology,obstet Gynecol,2009Dec,114,(6),1409:20 